\title{
Adverse Childhood Experiences and Alcohol Use Consumption Patterns among Vulnerable Urban Youth in Uganda
}

\author{
Nina K. Babihuga ${ }^{1}$, Monica H Swahn ${ }^{1 *}$, Shanta R. Dube ${ }^{1}$ and Rogers Kasirye ${ }^{2}$ \\ ${ }^{1}$ School of Public Health, Georgia State University P.O. Box 3995 Atlanta, GA 30302-3995 \\ ${ }^{2}$ Uganda Youth Development Link P.O. Box 12659 Kampala, Uganda \\ Corresponding Author: Monica H Swahn, Department of Population Health Sciences, School of Public Health, Georgia State University P.O. \\ Box 3995 Atlanta, GA 30302-3995, Email: mswahn@gsu.edu.
}

Received date: March 02, 2020; Accepted date: August 28, 2020; Published date: September 17, 2020

Citation: Nina K. Babihuga, Monica H Swahn, Shanta R. Dube and Rogers Kasirye; Adverse Childhood Experiences and Alcohol Use Consumption Patterns among Vulnerable Urban Youth in Uganda, J. Addiction Research and Adolescent Behaviour 3(1); DOI: 10.31579/2688$7517 / 017$

Copyright: ( ) 2020, Nina K. Babihuga. This is an open access article distributed under the Creative Commons Attribution License, which permits unrestricted use, distribution, and reproduction in any medium, provided the original work is properly cited.

\begin{abstract}
Purpose: Youth living in the urban slums in Uganda have many unmet needs. The purpose of the current study is to examine the associations between Adverse Childhood Experiences (ACEs) and alcohol use patterns, an understudied area among urban vulnerable youth, in order to provide guidance and insight for service provision for youth in resource-limited settings.

Methods: The current data analysis is based on a cross-sectional survey conducted in June 2011 which consisted of a convenience sample of youth ages 14-24 years, living in the slums ( $\mathrm{N}=457)$. Youth were recruited at drop-in centers hosted by the Uganda Youth Development Link (UYDE). Descriptive statistics were computed. Bivariate and multivariate logistic regression analyses were used to determine psychosocial correlates with being an orphan.

Results: Factors associated with alcohol use varied by sex ( $\mathrm{p}<.05)$ (alcohol use was more common among girls), age ( $\mathrm{p}<.0001)$, (alcohol use more common among youth 18 years of age and older) and alcohol use were also more common among youth who reported the following ACEs; parents hitting each other $(\mathrm{p}<.0001)$, parental use of alcohol $(\mathrm{p}<.0001)$, being hungry ( $<<.0001)$ having ever lived on the street $(\mathrm{p}<.0001)$ and having been raped $(\mathrm{p}<.0001)$.

Conclusions: The prevalence of ACEs were high in this study population which is a great concern. Moreover ACEs were associated with earlier age of alcohol use initiation and frequent and heavy drinking. Our findings underscore the need for early alcohol prevention and intervention strategies for these youth as well as support for the ACEs they have experienced.
\end{abstract}

Keywords: adverse childhood experiences; alcohol use consumption; vulnerable urban youth

\section{Introduction}

Globally, alcohol is the third-leading risk factor for premature death and disability [1] and it accounts for $5.9 \%$ of all deaths and $5.1 \%$ of the disease burden [2]. The World Health Organization (WHO) has highlighted the detrimental use of alcohol globally including causing disease, social and economic burden in societies [3]. The disease burden has been found to be closely linked to volume of alcohol consumption, with disproportionate effects on poor people and those marginalized in society [4].

Alcohol use has been found to be associated with alcohol dependence $[5,6]$, other substance use [6], criminal activity [6], unintentional injuries [5, 7], suicidal ideation and attempts [8], and is an important risk factor for chronic disease and injury $[9,10]$. Recent research findings also show strong associations between harmful alcohol use and infectious diseases such as tuberculosis and HIV/AIDS [11]. Findings have also shown differences and historical trends in alcohol consumption and related harm, which can be explained by environmental factors such as economic development, culture, availability of alcohol and the level and effectiveness of alcohol policies [12].
Correlates of alcohol use include: genetic factors [12, 13], age [12], gender [12, 14 and 15], family characteristics [12, 16], socio economic status [12, 17], culture [12] and child maltreatment [18, 19]. Findings on alcohol consumption particularly in Africa have shown that alcohol use and risky sexual behaviors are linked to drinking venues and alcohol serving establishments, sexual coercion, and poverty [21, 22]. These results point to the pressing public health issue of alcohol use in sub- Saharan Africa which is linked to other health-risk behaviors and adverse outcomes.

Alcohol use among youth, as a result of ACEs (Adverse Childhood Experiences), is an important public health concern because of the many detrimental health and social outcomes associated with its use [23]. However, despite the vast literature on alcohol use and ACEs, there is limited research on alcohol use and ACEs among youth in Uganda, particularly urban youth who do not attend school. This is concerning because these vulnerable youth are at a high risk for alcohol use at young ages and also for drinking frequently and heavily [24]. As such, this study seeks to examine alcohol drinking patterns and ACEs, that is; early alcohol use initiation, 
frequent and heavy drinking with the goal of informing program planning and intervention strategies.

A key area that has yet to be explored is the role of ACEs in early alcohol use initiation and consumption patterns. Research on ACEs in the U.S. demonstrate long term health consequences [20]. For example, experiencing 2 or more ACEs increase the risk of early alcohol use and alcohol dependence, psychological distress and self-reported alcohol problems $[6,25]$. Intriguingly, there are also differences in how ACEs affect men and women [6, 25]. Overall, there are strong associations between ACEs and early alcohol use and alcohol consumption patterns. Alcohol use is frequently used as a coping strategy for adversity, particularly in research among youth in North America and Europe. It is very likely that youth in sub-Saharan Africa, and in Kampala specifically, will have similar experiences. Previous research among the youth living in the slums and streets of Kampala has shown that $30.2 \%$ report problem drinking and $32.8 \%$ report drunkenness [24].

The following study was guided by two research questions: What is the prevalence and socio demographic correlates of ACEs among high -risk youth living in the slums of Kampala? Do high-risk youth living in the slums of Kampala who report ACEs initiate alcohol use earlier and use alcohol frequently and heavily than those who did not experience ACEs? In this study, ACEs were broadly defined and used as indicators to reflect whether youth were orphans, whether they actively talked to their parents, whether they saw their parents hitting each other, whether they were hit by their parents, whether their parents used alcohol, whether they experienced food insufficiency/ hunger, whether they had ever been homeless and lived on the street and whether they had been raped. These indicators were selected as a results of extensive previous research [12,24,26,27,28]. Moreover, alcohol use initiation ( $\leq 13$ years and $>13$ years) was a key outcome as it is an important metric for efforts to delay and reduce alcohol use.

Youth in the slums of Kampala, many of whom are orphans, often lack many of the basic needs [24,26,29], rarely attend school and are particularly vulnerable to a range of health risks including substance abuse [30]. As such, public health interventions are needed to address these concerns and mitigate the outcomes. The current study is conducted to inform prevention strategies with respect to ACEs and alcohol use in resource-poor settings.

\section{Methods}

Data from the 2011 Kampala Youth Survey was used for the analyses. The study protocol was approved by the Georgia State University Institutional Review Board and by the Uganda National Council for Science and Technology. The main objective of this crosssectional survey $(\mathrm{N}=457)$ was to quantify high-risk behaviors in a convenience sample of urban youth living on the streets or in the slums, 14-24 years of age, who were participating in a Uganda Youth Development Link (UYDEL) drop-in center. UYDEL is a non-profit organization seeks to enhance human capital development among the disadvantaged youth in the areas of child rights protection, HIV prevention, substance abuse, sexual and reproductive health, skills training and social research [31]. Face-to- face surveys, lasting about 30 minutes, were administered by UYDEL social workers or peer educators. Detailed methodology from the cross-sectional study has been reported previously [26, 27].

\section{Participant Selection, Inclusion and Exclusion Criteria}

The youth who were selected to be a part of the study were receiving services from any of UYDEL's 8 drop-in centers for street youth (UYDEL, 2013), which at that time, served approximately 650 youth per month. For the present study, 507 youth were approached to participate in the survey. Among these, 46 declined and 461 agreed to participate, yielding a participation rate of $90.9 \%$. Four surveys were missing substantial numbers of responses and were therefore excluded, yielding 457 completed surveys for the final analytic sample of youth between the ages of 14 and 24 (31.1\% boys and $68.5 \%$ girls).

\section{Measures}

Several variables informed by previous research [12] and the CDC ACE Study questionnaire [28], were used in the analysis to examine associations between adverse experiences and alcohol use status. Independent variables included were hunger, orphan status, talking to parents, ever having lived on the street, witnessing parents hitting each other, parents hitting each other, parents hitting children and parental use of alcohol. These variables were dichotomized to reflect the presence or absence of these risk factors. For all selected variables, all missing values were excluded.

\section{Indicators of ACES}

The eight measures used as broad indicators of ACEs are described below; having parents - Participants were asked if their parents (fathers and mothers) were alive at the time of the survey (Categories were: yes, no and N/A were categorized as absence of the indicator). Talking to parents - Participants were asked how often they talked to their fathers and mothers (Categories were: 'Yes' for daily, weekly, monthly and annually or 'no' for never). Parents hitting each other - Participants were asked if they had seen or heard their parents hitting each other (Categories were: yes, no and N/A were categorized as absence of the indicator). Parents hitting you Participants were asked if they had ever been hit or beaten by their parents (Categories were: yes, no and N/A were categorized as absence of the indicator). Parental use of alcohol - Participants were asked if their parents used alcohol (Categories were: yes, no and N/A were categorized as absence of the indicator). Hunger - Participants were asked if they were ever hungry (Categories were: yes, no and N/A were categorized as absence of the indicator). Having ever lived on the street - Participants were asked if they had ever lived on the streets or were currently living on the streets (Categories were: yes, no and N/A were categorized as absence of the indicator). Having been raped - Participants were asked if they had ever been raped (Categories were: yes, no and N/A were categorized as absence of the indicator).

The three outcome measures of interest were measured by; age of alcohol initiation ( $\leq 13$ years or $>13$ years), frequency of drinking and heavy drinking. All three categorical measures were coded to have three levels - presence or absence of the measure under study and the third level was non-drinkers who served as the reference group. Drinking status was assessed by participants' response to the question "In the past month, on how many days did you drink alcohol? (Current drinking)"; Age of alcohol use initiation was assessed by participants' response to the question "How old were you when you had your first drink of alcohol? Heavy drinking was indicated for respondents who drank so much that they were really drunk on 5 or more days.

\section{Independent Variables}

Indicators to measure ACEs were informed by the World Health Organization [12] and the CDC ACE Study questionnaire [28] and included; hunger, having parents, talking to parents, ever having lived on the street, having ever been raped, parents hitting each other, parents hitting the youth and parental use of alcohol.

\section{Data Analysis}

Three statistical techniques were used; Chi-Square tests of 
associations, Bivariate and Multivariate multinomial logistic regression analyses were computed to determine statistical association between ACEs and each of the three alcohol use outcomes among youth. Analyses were conducted using the SPSS statistical software package version 21. Initial bivariate analyses were performed. Measures with significant associations with the outcome variables were also examined in multivariate analyses. All independent variables were dichotomized to indicate the presence or absence of the particular risk factor. The three dependent variables had three levels that is; age of initiation (age 13 or under, over age 13, and nondrinkers), frequent drinking and heavy drinking (5 days or less, more than 5 days and non-drinkers).

\section{Results}

The description of indicators used in this study among Kampala youth are presented in Table 1. The prevalence of ACEs and their distribution by demographic characteristics are presented in Table 2 . In this study, $36.5 \%$ reported that they did not talk to their mother, $58.4 \%$ did not talk to their father, $32.4 \%$ had lost their mother, $51.6 \%$ had lost their father, $62.6 \%$ reported being hit by their parents, $30.9 \%$ had witnessed their parents hitting each other, $38.9 \%$ reported parental alcohol use, $60.6 \%$ reported hunger, $22.1 \%$ reported having ever lived on the street while $24.1 \%$ reported having been raped.

\begin{tabular}{|l|l|}
\hline Variable name (N) & Variable description \\
\hline Sex & What is your sex? \\
\hline Age & How old are you? \\
\hline Education & Do you go to school? \\
\hline Dad living & Is your dad living? \\
\hline Mom living & Is your mom living? \\
\hline Talk to dad & How often do you talk to your dad? \\
\hline Talk to mom & How often do you talk to your mom? \\
\hline Parents hit each other & Did you ever see or hear your parents hit/beat each other? \\
\hline Parents hit you & Did your parents ever hit/beat you? \\
\hline Parents use alcohol & Did your parents use alcohol? \\
\hline Hunger & Do you ever go hungry? \\
\hline Ever lived on the street & Indicate if child is currently or in the past has lived on the street \\
\hline Rape & Has someone ever raped you or forced you to have sex with him/her? \\
\hline Age of first drink & How old were you when you had your first drink of alcohol? \\
\hline Frequent Drinking & In the past month, On how many days did you drink alcohol? \\
\hline Heavy Drinking & In the past month, How many days did you drink so much that you were really drunk? \\
\hline
\end{tabular}

Table 1. Variable name and description of variables examined in the Kampala Youth Survey (2011)

The Demographic characteristics and ACEs indicators by gender are presented in Table 2. Chi-square tests of association were performed to identify differences between boys and girls on other demographic variables and ACEs. Results showed that boys' and girls' differed significantly with respect to reports of parental alcohol use $(p<.05)$, being hungry $(p<.001)$, ever having lived on the street $(p<.001)$ and having been raped $(\mathrm{p}<.001)$. Parental alcohol use, being hungry, and ever having lived on the street were common among girls while having been raped was more common among boys.

The characteristics and indicators' association with alcohol use are presented in Table 3. Factors associated with alcohol use varied by sex $(\mathrm{p}<.05)$ (alcohol use was more common among girls), age ( $\mathrm{p}<.0001)$, (alcohol use more common among youth 18 years of age and older) and alcohol use were also more common among youth who reported the following ACEs; parents hitting each other $(\mathrm{p}<.0001)$, parental use of alcohol $(\mathrm{p}<.0001)$, being hungry $(\mathrm{p}<.0001)$, having ever lived on the street $(\mathrm{p}<.0001)$ and having been raped $(\mathrm{p}<.0001)$.

Bivariate associations between alcohol use initiation, frequency of alcohol use, intensity of alcohol use and ACEs among youth living in the slums of Kampala are presented in Table 4. Bivariate multilogistic regression analyses were performed to examine associations between ACEs and early alcohol use initiation, frequent drinking and heavy drinking

Early alcohol use initiation was defined as youth who started drinking at or prior to age 13 . The reference category was nondrinkers. Parents hitting each other $(\mathrm{OR}=2.30 ; 95 \% \mathrm{CI}: 1.22-4.35)$, parents use of alcohol (OR=7.21; 3.66-14.20), hunger (OR=4.55; 95\%CI: 2.06-10.10), ever lived on the streets $(\mathrm{OR}=4.84 ; 95 \% \mathrm{CI}: 2.41-9.72)$ and rape $(\mathrm{OR}=3.22$; 95\%CI: 1.63-6.35) were associated with alcohol use initiation prior to age 13 (Table 4). Similarly, parents hitting each other $(\mathrm{OR}=2.89$; 95\%CI: 1.85-4.54), parents use of alcohol $(\mathrm{OR}=4.50 ; 2.86-7.10)$, hunger $(\mathrm{OR}=2.09$; 95\% CI: 1.34-3.29), ever lived on the streets $(\mathrm{OR}=4.95$; 95\%CI: 2.94-8.32) and rape $(\mathrm{OR}=4.73$; 95\% CI: 2.89-7.72) were associated with alcohol use initiation after age 13. Talking to mom or dad or whether mom or dad were living were not associated with age of alcohol use initiation.

In terms of frequent drinking, parents hitting each other $(\mathrm{OR}=3.62 ; 95 \% \mathrm{CI}: 2.01-6.52)$, parents use of alcohol $(\mathrm{OR}=6.01 ; 3.16-$ 11.40), hunger $(\mathrm{OR}=3.06$; 95\%CI: 1.56-5.99), ever lived on the streets $\quad(\mathrm{OR}=8.62 ; 95 \% \mathrm{CI}: 4.63-16.04)$ and rape $\quad(\mathrm{OR}=5.75$; 95\%CI:3.16-10.46) were associated with drinking on more than 5 days in the past month. Similarly, parents hitting each other $(\mathrm{OR}=2.26$; 95\% CI: 1.35-3.79), parents use of alcohol $(\mathrm{OR}=3.79$; 2.24-6.45), hunger $(\mathrm{OR}=2.31$; 95\% CI: 1.33-4.03), ever lived on the streets $(\mathrm{OR}=4.45 ; 95 \% \mathrm{CI}: 2.50-7.92)$ and rape $(\mathrm{OR}=3.54 ; 95 \% \mathrm{CI}$ : 2.05-6.12) were associated with drinking less than 5 days in the past month. Talking to mom or dad, whether mom or dad were living, or whether parents hit you, were not associated with frequent drinking.

In terms of heavy drinking, or drinking until drunk, parents use of alcohol $(\mathrm{OR}=3.49 ; 95 \% \mathrm{CI}$ : 1.55-7.88), ever lived on the streets $(\mathrm{OR}=10.52 ; 95 \% \mathrm{CI}: 4.69-23.60)$ and rape $(\mathrm{OR}=2.81$; 95\% CI:1.27-6.21) were associated with heavy drinking on more than 5 days in the past month. Similarly, parents hitting each other $(\mathrm{OR}=2.81 ; 95 \% \mathrm{CI}: 1.69-4.66)$, parents use of alcohol $(\mathrm{OR}=4.45$; 95\%CI: 2.61-7.60), hunger $(\mathrm{OR}=2.99$; 95\%CI:1.66-5.39), ever lived on the streets $(\mathrm{OR}=6.09 ; 95 \% \mathrm{CI}: 3.51-10.57)$ and rape $(\mathrm{OR}=5.23$; 95\% CI:3.09-8.83) were associated with heavy drinking on less than 5 days in the past month. Talking to mom or dad, whether mom or dad were living, or whether parents hit you, were not associated with heavy drinking. 


\begin{tabular}{|c|c|c|c|c|c|c|}
\hline Variable name & $\mathbf{N}(\%)$ & Categories & \% Boys & $\%$ Girls & Total & $P$ value \\
\hline Age & $452(98.9)$ & $\begin{array}{l}\leq 18 \\
\geq 18\end{array}$ & $\begin{array}{l}19.9 \\
11.5\end{array}$ & $\begin{array}{l}38.1 \\
30.5\end{array}$ & $\begin{array}{l}58.0 \\
42.0\end{array}$ & .114 \\
\hline Education & $453(99.1)$ & $\begin{array}{l}\text { In school } \\
\text { Out of school }\end{array}$ & $\begin{array}{l}3.8 \\
27.6\end{array}$ & $\begin{array}{l}10.6 \\
58.1\end{array}$ & $\begin{array}{l}14.3 \\
85.7\end{array}$ & .329 \\
\hline Talk to mom & $453(99.1)$ & $\begin{array}{l}\text { Yes } \\
\text { No }\end{array}$ & $\begin{array}{l}19.4 \\
11.9\end{array}$ & $\begin{array}{l}43.7 \\
24.9\end{array}$ & $\begin{array}{l}63.1 \\
36.9\end{array}$ & .729 \\
\hline Talk to dad & $451(98.7)$ & $\begin{array}{l}\text { Yes } \\
\text { No }\end{array}$ & $\begin{array}{l}13.1 \\
18.0\end{array}$ & $\begin{array}{l}27.7 \\
41.2\end{array}$ & $\begin{array}{l}40.8 \\
59.2\end{array}$ & .697 \\
\hline Mom living & $448(98.0)$ & $\begin{array}{l}\text { Yes } \\
\text { No }\end{array}$ & $\begin{array}{l}21.2 \\
9.6\end{array}$ & $\begin{array}{l}45.8 \\
23.4\end{array}$ & $\begin{array}{l}67.0 \\
33.0\end{array}$ & .573 \\
\hline Dad living & $448(98.0)$ & $\begin{array}{l}\text { Yes } \\
\text { No }\end{array}$ & $\begin{array}{l}16.5 \\
14.7\end{array}$ & $\begin{array}{l}30.8 \\
37.9\end{array}$ & $\begin{array}{l}47.3 \\
52.7\end{array}$ & .114 \\
\hline Parents hit each other & $443(96.9)$ & $\begin{array}{l}\text { Yes } \\
\text { No }\end{array}$ & $\begin{array}{l}12.0 \\
19.2\end{array}$ & $\begin{array}{l}19.6 \\
49.2\end{array}$ & $\begin{array}{l}31.6 \\
68.4\end{array}$ & $.038^{*}$ \\
\hline Parents hit you & $443(96.9)$ & $\begin{array}{l}\text { Yes } \\
\text { No }\end{array}$ & $\begin{array}{l}19.6 \\
11.7\end{array}$ & $\begin{array}{l}44.5 \\
24.2\end{array}$ & $\begin{array}{l}64.1 \\
35.9\end{array}$ & .652 \\
\hline Parents use alcohol & $434(95.0)$ & $\begin{array}{l}\text { Yes } \\
\text { No }\end{array}$ & $\begin{array}{l}15.0 \\
15.2\end{array}$ & $\begin{array}{l}25.8 \\
44.0\end{array}$ & $\begin{array}{l}40.8 \\
59.2\end{array}$ & $.014 *$ \\
\hline Hunger & $445(97.4)$ & $\begin{array}{l}\text { Yes } \\
\text { No }\end{array}$ & $\begin{array}{l}23.1 \\
7.4\end{array}$ & $\begin{array}{l}38.7 \\
30.8\end{array}$ & $\begin{array}{l}61.8 \\
38.2\end{array}$ & $<.0001 *$ \\
\hline Ever lived on street & $416(91.0)$ & $\begin{array}{l}\text { Yes } \\
\text { No }\end{array}$ & $\begin{array}{l}9.9 \\
19.0\end{array}$ & $\begin{array}{l}14.4 \\
56.7\end{array}$ & $\begin{array}{l}24.3 \\
75.7\end{array}$ & $.003 *$ \\
\hline Raped & $446(97.6)$ & $\begin{array}{l}\text { Yes } \\
\text { No }\end{array}$ & $\begin{array}{l}19.5 \\
11.7\end{array}$ & $\begin{array}{l}5.2 \\
63.7\end{array}$ & $\begin{array}{l}24.7 \\
75.3\end{array}$ & $<.0001 *$ \\
\hline
\end{tabular}

Chi-square tests of association between boys and girls for demographic characteristics and ACEs

*Indicates $\mathrm{p}<.05$

Table 2. Demographic characteristics and ACEs measures across gender among Kampala youth $(\mathrm{N}=457)$

\begin{tabular}{|c|c|c|c|c|c|c|}
\hline Variable name & $\mathbf{N}(\%)$ & Categories & Alcohol Use \% & $\begin{array}{l}\text { Alcohol non-Use } \\
\%\end{array}$ & Total alcohol use & $P$ value \\
\hline Sex & $455(99.6)$ & $\begin{array}{l}\text { Boys } \\
\text { Girls }\end{array}$ & $\begin{array}{l}12.1 \\
17.8\end{array}$ & $\begin{array}{l}19.1 \\
51.0\end{array}$ & $\begin{array}{l}29.9 \\
70.1\end{array}$ & $.006^{*}$ \\
\hline Age & $454(99.3)$ & $\begin{array}{l}\leq 18 \\
\geq 18\end{array}$ & $\begin{array}{l}11.0 \\
19.2\end{array}$ & $\begin{array}{l}46.9 \\
22.9\end{array}$ & $\begin{array}{l}30.2 \\
69.8\end{array}$ & $<.0001^{*}$ \\
\hline Education & 455 (99.6) & $\begin{array}{c}\text { In school } \\
\text { Out of school }\end{array}$ & $\begin{array}{l}4.0 \\
25.9\end{array}$ & $\begin{array}{l}10.5 \\
59.6\end{array}$ & $\begin{array}{l}29.9 \\
70.1\end{array}$ & .615 \\
\hline Talk to mom & 455 (99.6) & $\begin{array}{l}\text { Yes } \\
\text { No }\end{array}$ & $\begin{array}{l}27.1 \\
35.3\end{array}$ & $\begin{array}{l}72.9 \\
64.7\end{array}$ & $\begin{array}{l}30.1 \\
69.9\end{array}$ & .065 \\
\hline Talk to dad & $453(99.1)$ & $\begin{array}{l}\text { Yes } \\
\text { No }\end{array}$ & $\begin{array}{l}27.4 \\
32.2\end{array}$ & $\begin{array}{l}72.6 \\
67.8\end{array}$ & $\begin{array}{l}30.2 \\
69.8\end{array}$ & .275 \\
\hline Mom living & $450(98.5)$ & $\begin{array}{l}\text { Yes } \\
\text { No }\end{array}$ & $\begin{array}{l}27.5 \\
35.1\end{array}$ & $\begin{array}{l}72.5 \\
64.9\end{array}$ & $\begin{array}{l}30.0 \\
70.0\end{array}$ & .096 \\
\hline Dad living & $450(98.5)$ & $\begin{array}{l}\text { Yes } \\
\text { No }\end{array}$ & $\begin{array}{l}29.0 \\
30.9\end{array}$ & $\begin{array}{l}71.0 \\
69.1\end{array}$ & $\begin{array}{l}30.0 \\
70.0\end{array}$ & .650 \\
\hline Parents hit each other & 445 (97.4) & $\begin{array}{l}\text { Yes } \\
\text { No }\end{array}$ & $\begin{array}{l}44.7 \\
22.7\end{array}$ & $\begin{array}{l}55.3 \\
77.3\end{array}$ & $\begin{array}{l}29.7 \\
70.3\end{array}$ & $<.0001^{*}$ \\
\hline Parents hit you & $445(97.4)$ & $\begin{array}{l}\text { Yes } \\
\text { No }\end{array}$ & $\begin{array}{l}32.5 \\
24.5\end{array}$ & $\begin{array}{l}67.5 \\
75.5\end{array}$ & $\begin{array}{l}29.7 \\
70.3\end{array}$ & .077 \\
\hline Parents use alcohol & $436(95.4)$ & $\begin{array}{l}\text { Yes } \\
\text { No }\end{array}$ & $\begin{array}{l}47.8 \\
16.7\end{array}$ & $\begin{array}{l}52.2 \\
83.3\end{array}$ & $\begin{array}{l}29.4 \\
70.6\end{array}$ & $<.0001^{*}$ \\
\hline Hunger & 447 (97.8) & $\begin{array}{l}\text { Yes } \\
\text { No }\end{array}$ & $\begin{array}{l}37.5 \\
18.8\end{array}$ & $\begin{array}{l}62.5 \\
81.2\end{array}$ & $\begin{array}{l}30.4 \\
69.6\end{array}$ & $<.0001^{*}$ \\
\hline Ever lived on street & $418(91.5)$ & $\begin{array}{l}\text { Yes } \\
\text { No }\end{array}$ & $\begin{array}{l}62.4 \\
21.8\end{array}$ & $\begin{array}{l}37.6 \\
78.2\end{array}$ & $\begin{array}{l}31.6 \\
68.4\end{array}$ & $<.0001^{*}$ \\
\hline Raped & $448(98.0)$ & $\begin{array}{l}\text { Yes } \\
\text { No }\end{array}$ & $\begin{array}{l}55.5 \\
22.2\end{array}$ & $\begin{array}{l}44.5 \\
77.8\end{array}$ & $\begin{array}{l}30.4 \\
69.6\end{array}$ & $<.0001^{*}$ \\
\hline
\end{tabular}

Chi-square tests of association between alcohol use or non-use on demographic variables and ACEs *Indicates $\mathrm{p}<.05$

Table 3. Characteristics and risk factors' association with alcohol use among Kampala youth $(\mathrm{N}=457)$ 


\begin{tabular}{|c|c|c|c|c|c|c|}
\hline \multirow{3}{*}{ Variable name } & \multicolumn{2}{|c|}{ Age of alcohol initiation } & \multicolumn{2}{|c|}{ Frequent drinking } & \multicolumn{2}{|c|}{ Heavy drinking } \\
\hline & OR $(95 \%$ CI $)$ & & OR $(95 \%$ CI $)$ & & OR $(95 \%$ CI $)$ & \\
\hline & $\leq 13$ years & $>13$ years & $\leq 5$ days & $>5$ days & $\leq 5$ & $>5$ \\
\hline Talk to mom & $0.65(0.36-1.19)$ & $0.91(0.59-1.40)$ & $.58(.35-.96)$ & $.84(.47-1.50)$ & $1.68(.41-1.11)$ & $2.69(.32-1.47)$ \\
\hline Talk to dad & $0.84(0.46-1.56)$ & $0.77(0.50-1.18)$ & $.621(.37-1.05)$ & $1.09(.62-1.91)$ & $1.77(.46-1.27)$ & $.78(.36-1.69)$ \\
\hline Mom living & $0.78(0.42-1.45)$ & $0.90(0.58-1.41)$ & $.65(.39-1.09)$ & $.77(.43-1.39)$ & $.74(.44-1.23)$ & $.68(.32-1.46)$ \\
\hline Dad living & $0.97(0.53-1.76)$ & $0.96(0.63-1.46)$ & $.75(.45-1.23)$ & $1.19(.68-2.09)$ & $1.01(.62-1.64)$ & $.77(.36-1.65)$ \\
\hline Parents hit each other & $2.30(1.22-4.35)$ & $2.89(1.85-4.54)^{*}$ & $2.26(1.35-3.79)$ & $3.62(2.01-6.52)^{*}$ & $2.81(1.69-4.66)$ & $1.77(.79-3.92)^{*}$ \\
\hline Parents hit you & $1.31(0.69-2.47)$ & $1.85(1.16-2.93)^{*}$ & $1.49(.87-2.59)$ & $1.46(.79-2.69)$ & $1.53(.88-2.65)$ & $.76(.36-1.63)$ \\
\hline Parents use alcohol & $7.21(3.66-14.2)$ & $4.50(2.86-7.10)^{*}$ & $3.79(2.24-6.45)$ & $6.01(3.16-11.40)^{*}$ & $4.45(2.61-7.60)$ & $3.49(1.55-7.88)^{*}$ \\
\hline Hunger & $4.55(2.06-10.1)$ & $2.09(1.34-3.29)^{*}$ & $2.31(1.33-4.03)$ & $3.06(1.56-5.99)^{*}$ & $2.99(1.66-5.39)$ & $2.09(.91-4.83)^{*}$ \\
\hline Ever lived on street & $4.84(2.41-9.72)$ & $4.95(2.94-8.32)^{*}$ & $4.45(2.50-7.92)$ & $8.62(4.63-16.04)^{*}$ & $6.09(3.51-10.57)$ & $10.52(4.69-23.6)^{*}$ \\
\hline Raped & $3.22(1.63-6.35)$ & $4.73(2.89-7.72)^{*}$ & $3.54(2.05-6.12)$ & $5.75(3.16-10.46)^{*}$ & $5.23(3.09-8.83)$ & $2.81(1.27-6.21)^{*}$ \\
\hline *Indicates $\mathrm{p}<.05$ & & & & & & \\
\hline
\end{tabular}

Table 4. Bivariate associations between age of alcohol use initiation, frequent, heavy drinking and ACEs among youth living in the slums of Kampala $(\mathrm{N}=457)$

\begin{tabular}{|c|c|c|c|c|}
\hline Variable name & $\mathbf{N}(\%)$ & \multicolumn{2}{|c|}{$\operatorname{AOR}(95 \% \mathrm{CI})$} & P value \\
\hline \multicolumn{5}{|c|}{ Age of alcohol use initiation } \\
\hline & & $\leq 13$ years & $>13$ years & \\
\hline Parents hit each other & $445(97.4)$ & $.90(.40-2.05)$ & $1.62(.88-2.98)$ & .196 \\
\hline Parents hit you & $445(97.4)$ & $.98(.44-2.21)$ & $1.54(.82-2.88)$ & .357 \\
\hline Parents use alcohol & $436(95.4)$ & $5.43(2.47-11.94)$ & $3.28(1.85-5.80)$ & $<.0001^{*}$ \\
\hline Hunger & $447(97.8)$ & $2.42(.92-6.34)$ & $.88(.48-1.59)$ & .115 \\
\hline Ever lived on street & $418(91.5)$ & $3.67(1.61-8.37)$ & $3.34(1.72-6.49)$ & $<.0001^{*}$ \\
\hline Raped & $448(98.0)$ & $2.17(.93-5.05)$ & $3.89(2.06-7.33)$ & $<.0001^{*}$ \\
\hline \multicolumn{5}{|c|}{ Frequent drinking } \\
\hline & & $\leq 5$ days & $>5$ days & \\
\hline Parents hit each other & $445(97.4)$ & $1.42(.76-2.66)$ & $1.96(.95-4.05)$ & .174 \\
\hline Parents use alcohol & $436(95.4)$ & $3.24(1.73-6.05)$ & $4.04(1.88-8.65)$ & $<.0001^{*}$ \\
\hline Hunger & $447(97.8)$ & $1.06(.54-2.10)$ & $1.11(.46-2.69)$ & .964 \\
\hline Ever lived on street & $418(91.5)$ & $3.45(1.75-6.81)$ & $4.67(2.18-9.99)$ & $<.0001^{*}$ \\
\hline Raped & $448(98.0)$ & $2.49(1.27-4.93)$ & $4.81(2.29-10.12)$ & $<.0001^{*}$ \\
\hline \multicolumn{5}{|c|}{ Heavy drinking } \\
\hline & & $\leq 5$ days & $>5$ days & \\
\hline Parents hit each other & $445(97.4)$ & $1.43(.76-2.69)$ & $.92(.36-2.37)$ & .484 \\
\hline Parents use alcohol & $436(95.4)$ & $3.29(1.72-6.30)$ & $3.31(1.27-8.66)$ & $<.0001^{*}$ \\
\hline Hunger & $447(97.8)$ & $1.24(.59-2.59)$ & $.73(.24-2.22)$ & .688 \\
\hline Ever lived on street & $418(91.5)$ & $3.41(1.75-6.63)$ & $9.38(3.51-25.05)$ & $<.0001^{*}$ \\
\hline Raped & $448(98.0)$ & $3.59(1.89-6.84)$ & $2.70(1.04-7.03)$ & $<.0001^{*}$ \\
\hline
\end{tabular}

Table 5. Multivariate associations between alcohol use (initiation, frequency and heavy drinking) and ACEs among youth living in the slums of Kampala $(\mathrm{N}=457)$ 
The multivariate associations between alcohol use patterns (i.e., age of alcohol use initiation, frequency and heavy drinking) and ACEs among youth living in the slums of Kampala are presented in Table 5. Multivariate analysis were performed on the measures that were statistically significant in bivariate analyses (Table 4). Results indicated that parental use of alcohol, having ever lived on the street and having been raped were significantly associated with all three outcomes, age of alcohol initiation, frequent drinking and heavy drinking.

In multivariate analyses of age of alcohol initiation, parental use of alcohol (AOR=5.43; 95\% CI:2.47-11.94), having ever lived on the street $(\mathrm{AOR}=3.67 ; 95 \% \mathrm{CI}: 1.61-8.37)$, and having been raped $(\mathrm{AOR}=2.17$; 95\% CI:.93-5.05) were associated with alcohol use initiation prior to age 13 .

In multivariate analyses of frequent drinking, parental use of alcohol (AOR=3.24; 95\% CI:1.73-6.05), having ever lived on the street (AOR=3.45; 95\% CI:1.75-6.81), and having been raped $(\mathrm{AOR}=2.49 ; 95 \% \mathrm{CI}: 1.27-4.93)$ were associated with drinking on more than 5 days in the past month.

In multivariate analyses of heavy drinking, parental use of alcohol $(\mathrm{AOR}=3.29 ; 95 \% \mathrm{CI}: 1.72-6.30)$, having ever lived on the street $(\mathrm{AOR}=3.41 ; 95 \% \mathrm{CI}: 1.75-6.63)$, and having been raped (AOR=3.59; 95\% CI: 1.89-6.84) were associated with heavy drinking on more than 5 days in the past month.

\section{Discussion}

The purpose of this study was to examine the association between ACEs and alcohol consumption patterns among youth living in slums in Kampala. Our findings show that several ACEs vary by sex and age and also are highly prevalent among these youth (i.e., parental alcohol use, being hungry, and ever having lived on the street were common among girls while having been raped was more common among boys). These findings of relatively high prevalence of ACEs (> $20 \%$ for each indicator) were expected because of the unique circumstances and disparities faced by these youth [26].

Our results show that several ACEs were strongly associated with all three outcomes (i.e., age of alcohol use initiation, frequent drinking and heavy drinking) in our multivariate analyses. The most important factors were parental use of alcohol, ever lived on the streets, and rape. First, the harm associated with ACEs, as presented in this study, are broadly consistent with previous research and reports of ACEs [30, 32-35]. Second, the relatively high levels of drinking and related problems have been reported among younger youth in the same setting [13, 26, 28, 29] and among school-attending youth in Uganda [24]. These findings indicate high unmet needs for alcohol prevention and treatment strategies suitable for low-resource settings. Third, it was surprising that several factors examined were not significantly associated with alcohol consumption patterns among these youth. In particular, parental communication, a proxy for parental involvement, was not significantly associated with alcohol use. Similarly, orphan hood in this study was also not significantly associated with any of the outcomes. These findings may reflect the unique circumstances of these youth or that parental involvement or presence is viewed differently in this context, particularly given the high levels of homelessness reported. However, it should also be noted that the study was originally not designed to assess these factors and the absence of associations may be merely reflected by the survey design. However, future research should examine the role of parental factors in more detail as some research has indicated the role of alcohol-related physical abuse and alcohol problems among younger youth in the same setting [13].
Fourth, significant gender differences were observed

among the independent variables assessed (i.e., parents hitting each other, parents use of alcohol, hunger, ever lived on the street, and rape). As such, these factors merit further investigation in terms of the potential gender differences in relationships with parents, homelessness, hunger and risk for rape victimization [28] which may impact young men and women differently.

Fifth, there is need to understand how alcohol use may be used as a coping strategy for ACEs in this context of youth who live in poverty and who experience high levels of disparities such as homelessness, food insufficiency and rape. Future research that seeks to understand the potential alternative coping strategies and to mitigate these experiences through empowerment and resilience in a lowresource setting, will be critically important. and are of great urgency.

This study, a first of its kind, examined the associations between ACEs and several alcohol measures in an under studied, vulnerable, urban population in Kampala, Uganda. This study underscore significant needs and also raises new and important research questions for more exploratory research and possibly interventions to address the urgent public health needs in this and similarly vulnerable populations.

The results stated here should be viewed in light of several limitations that should be considered when interpreting the findings. The study participants were not randomly selected, but were youth who self-selected to attend the drop-in centers and to take part of the study. Therefore, the findings may not be representative of street and slum youth in Kampala and may not be generalizable to populations elsewhere. The definition of youth who live in the slums was broad and included a range of circumstances and family contexts (both street youth who were homeless and youth who lived in the slums but may have had a stable living arrangement). Due to limited literacy rates, participants were read the questionnaire which could have led to biases, particularly under reporting of alcohol use or ACEs. Most of the questions regarding alcohol use and high-risk behaviors were selected from previously established self-administered surveys, specifically the Youth Risk Behavior Survey conducted in the U.S. and the Global School-based Student Health Survey conducted primarily in Africa, Asia, and Latin America where the wording of the questions used was simplified in most cases and the response options narrowed to facilitate the administration of the survey by the interviewers. As such, the reliability and validity of some of the measures may have been altered. Additionally, with the cross- sectional nature of the survey, the temporal ordering of ACEs and alcohol use outcomes cannot be determined, nor can causation be inferred. Finally, the findings are based on secondary analyses of a survey that was not specifically designed for ACEs. As such, we used several indicators of ACEs in these analyses.

Despite these limitations, the findings from this study indicate important needs and priorities for these youth, in particular with respect to alcohol prevention and likely also alcohol treatment. For public health practice, it is important to recognize that evidence-based strategies developed in North America and Europe, may not be relevant for a lowincome country such as Uganda or for vulnerable youth with particular needs and circumstances. With the limited healthcare resources available for treatment and prevention of infectious and chronic diseases among youth in the slums of Kampala, it is clear that public health issues such as alcohol use and ACEs have been given less priority. However, the findings from this study can be used to advocate for the urgency of providing more resources and services to these vulnerable youth, most of who have lost one or more parents and have faced significant ACEs thereby compounding existing problems including alcohol abuse and its rippling effects. Resources need to be focused on primary prevention of harmful alcohol use and ACEs among youth. 
Moreover, alcohol prevention and treatment services need to be considered complimentary to, and not competing with, other prevention efforts underway to address other critical health problems including disease, hunger and poverty.

Lastly, it is important to create a national child protection plan with local community support so that future interventions, policies, and resource allocation can produce the impact needed and to improve the conditions and health outcomes of children and vulnerable youth later in life. More specifically, including ACEs into alcohol prevention efforts among youth could prevent a number of negative consequences and have significant impact on a range of serious health problems [37]. Specifically, prevention efforts can be supported by collecting ACE data to inform policy makers, increasing awareness of ACEs nationwide and at the community- level, emphasizing the relevance of ACEs to multiple behavioral health disciplines, and using ACEs research and collected data to identify groups of people who may be at higher risk for substance abuse and related behavioral health problems and tailoring interventions to best assist them [38].

The WHO highlights the need for a multi-sectoral approach in preventing child maltreatment and to maximize the effects of prevention and care, and also recommends that interventions are delivered as part of a four-step public health approach: defining the problem; identifying causes and risk factors; designing and testing interventions aimed at minimizing the risk factors; disseminating information about the effectiveness of interventions and increasing the scale of proven effective interventions [39].

Additional research is needed to replicate these findings since they are primarily based on a convenience sample of youth who have sought out services offered by a drop-in center. As such, their experiences may be different than that of other youth and should be documented in greater detail and also preferably in a longitudinal cohort to better determine the initiation of risk behaviors and the identification of modifiable factors that may be suitable for interventions. Future research is also needed to better determine strategies for providing additional psychosocial support and treatment for these youths who may be difficult to reach. This is particularly troubling given the acute shortage of psychiatrists, psychologists, nurses, and social workers in Africa and Uganda specifically.

\section{Conclusion}

Our findings demonstrate that some ACEs are strongly associated with age of alcohol use initiation and also with frequent and heavy drinking among youth who live in the slums of Kampala, Uganda. As such, our findings indicate an urgent need to address these vulnerabilities and the counterproductive coping strategies youth may use. In particular early prevention of alcohol use, prior to age 13 is needed. Alcohol use has serious and long lasting implications over the life course, especially for those who experience adversity early in life. This is more pronounced among youth facing grave adversities and who lack adequate resources and support to improve their lives.

\section{Acknowledgment}

Research reported in this manuscript was conducted as part of an MPH thesis by the lead author Nina K. Babihuga under the supervision of the co-authors Drs. Swahn and Dube. We are very grateful to the Executive Director, Mr. Rogers Kasirye, his team at UYDEL and all the youth who participated in this study. We are also very grateful to the Office of International Initiatives at Georgia State University who funded this project.

\section{References}

1. Alcohol grows as risk factor for death and disability in 2010 GBD Study-IAS. Available: http://www.ias.org.uk/What-wedo/Publication-archive/The-Globe/Issue-1-2013/Alcohol-growsas-risk-factor-for-death-and-disability-in-2010-GBD-Study.aspx

2. World Health Organization. (2018). Global status report on alcohol and health 2018: executive summary. World Health Organization. Available: https://www.who.int/substance_abuse/ publications/global_alcohol_report/en/

3. The Global Strategy to reduce the harmful use of alcohol.2014.

4. Rehm, J., Mathers, C., Popova, S., Thavorncharoensap, M., Teerawattananon, Y., \& Patra, J. (2009). Global burden of disease and injury and economic cost attributable to alcohol use and alcohol-use disorders. Lancet, 373(9682), 2223-2233.

5. Hingson, R. W., Heeren, T., \& Winter, M. R. (2006). Age at drinking onset and alcohol dependence: Age at onset, duration, and severity. Archives of Pediatrics \& Adolescent Medicine, 160(7), 739-746.

6. NIAAA Publications AlcoholmUse Disorder. Available: https:// www.niaaa.nih.gov/alcohols-effects-health/alcohol-usedisorder

7. Hingson, R., Heeren, T., Zakocs, R., Winter, M., \& Wechsler, H. (2003). Age of First Intoxication, Heavy Drinking, Driving after Drinking and Risk of Unintentional Injury among U.S. College Students. Journal of Studies on Alcohol and Drugs, 64(1), 23.

8. Swahn, M. H., \& Bossarte, R. M. (2007). Gender, Early Alcohol Use, and Suicide Ideation and Attempts: Findings from the 2005 Youth Risk Behavior Survey. Journal of Adolescent Health, 41(2), 175-181.

9. Swahn, M. H., Culbreth, R., Tumwesigye, N. M., Topalli, V., Wright, E., \& Kasirye, R. (2018). Problem Drinking, AlcoholRelated Violence, and Homelessness among Youth Living in the Slums of Kampala, Uganda. International Journal of Environmental Research and Public Health, 15(6).

10. Seitz, H. K., \& Becker, P. (2007). Alcohol metabolism and cancer risk. Alcohol Research \& Health: The Journal of the National Institute on Alcohol Abuse and Alcoholism, 30(1), 3841, 44-47.

11. Taylor, B., Irving, H. M., Kanteres, F., Room, R., Borges, G., Cherpitel, C., Greenfield, T., \& Rehm, J. (2010). The more you drink, the harder you fall: A systematic review and meta-analysis of how acute alcohol consumption and injury or collision risk increase together. Drug and Alcohol Dependence, 110(1-2), 108-116.

12. WHO Global Strategy to Reduce the Harmful Use of Alcohol (2010).

13. Swahn, M. H., Culbreth, R. E., Staton, C. A., Self-Brown, S. R., \& Kasirye, R. (2017). Alcohol-Related Physical Abuse of Children in the Slums of Kampala, Uganda. International Journal of Environmental Research and Public Health, 14(10).

14. WHO | Global Status Report on Alcohol and Health 2014.

15. Genetics of Alcohol Use Disorder. (2014) National Institute on Alcohol Abuse and Alcoholism (NIAAA)

16. Grucza, R. A., Norberg, K., Bucholz, K. K., \& Bierut, L. J. (2008). Correspondence Between Secular Changes in Alcohol Dependence and Age of Drinking Onset Among Women in the United States. Alcoholism, Clinical and Experimental Research, 32(8), 1493-1501.

17. Wilsnack, R. W., \& Wilsnack, S. C. (2013). Gender and alcohol: Consumption and consequences. In Alcohol: Science, policy, and public health (pp. 153-160). Oxford University Press. 
18. Felitti, V. J., Anda, R. F., Nordenberg, D., Williamson, D. F., Spitz, A. M., Edwards, V., Koss, M. P., \& Marks, J. S. (1998). Relationship of childhood abuse and household dysfunction to many of the leading causes of death in adults. The Adverse Childhood Experiences (ACE) Study. American Journal of Preventive Medicine, 14(4), 245-258.

19. Grittner, U., Kuntsche, S., Graham, K., \& Bloomfield, K. (2012). Social Inequalities and gender differences in the experience of alcohol-related problems. Alcohol and Alcoholism (Oxford, Oxfordshire), 47 (5)597-605.

20. Springer, K. W., Sheridan, J., Kuo, D., \& Carnes, M. (2003). The Long-term Health Outcomes of Childhood Abuse. Journal of General Internal Medicine, 18(10), 864-870.

21. Shuper, P. A., Neuman, M., Kanteres, F., Baliunas, D., Joharchi, N., \& Rehm, J. (2010). Causal considerations on alcohol and HIV/AIDS--a systematic review. Alcohol and Alcoholism (Oxford, Oxfordshire), 45(2), 159-166.

22. Dube, Shanta R, Anda, R. F., Felitti, V. J., Edwards, V. J., \& Croft, J. B. (2002). Adverse childhood experiences and personal alcohol abuse as an adult. Addictive Behaviors, 27(5), 713-725.

23. Kalichman, S. C., Simbayi, L. C., Kaufman, M., Cain, D., \& Jooste, S. (2007). Alcohol use and sexual risks for HIV/ AIDS in sub-Saharan Africa: Systematic review of empirical findings. Prevention Science: The Official Journal of the Society for Prevention Research, 8(2), 141-151.

24. Swahn, M. H., Ali, B., Palmier, J., Tumwesigye, N. M., Sikazwe, G., Twa-Twa, J., \& Rogers, K. (2011). Early alcohol use and problem drinking among students in Zambia and Uganda. Journal of Public Health in Africa, 2(2).

25. The Health and Social Impact of Growing Up With Adverse Childhood Experiences.

26. Swahn, M. H., Palmier, J. B., \& Kasirye, R. (2013). Alcohol Exposures, Alcohol Marketing, and Their Associations with Problem Drinking and Drunkenness among Youth Living in the Slums of Kampala, Uganda. International Scholarly Research Notices, 2013, e948675.

27. Strine, T. W., Dube, S. R., Edwards, V. J., Prehn, A. W., Rasmussen, S., Wagenfeld, M., Dhingra, S., \& Croft,J. B. (2012). Associations between adverse childhood experiences, psychological distress, and adult alcohol problems. American Journal of Health Behavior, 36(3), 408-423.

28. Swahn, M. H., Gressard, L., Palmier, J. B., Kasirye, R., Lynch, C., \& Yao, H. (2012). Serious Violence Victimization and Perpetration among Youth Living in the Slums of Kampala, Uganda. The Western Journal of Emergency Medicine, 13(3), 253-259.
Swahn, M. H., Palmier, J. B., Kasirye, R., \& Yao, H. (2012). Correlates of Suicide Ideation and Attempt among Youth Living in the Slums of Kampala. International Journal of Environmental Research and Public Health, 9(2), 596-609.

30. CDCAdverse Childhood Experiences (ACEs) Available: https://www.cdc.gov/violenceprevention/aces/ index.html

31. Swahn, M. H., Ali, B., Palmier, J. B., Sikazwe, G., \& Mayeya, J. (2011). Alcohol Marketing, Drunkenness, and Problem Drinking among Zambian Youth: Findings from the 2004 Global SchoolBased Student Health Survey. Journal of Environmental and Public Health, 2011, e497827.

32. Uganda Youth Development Link.Available: https:// www.uydel.org/

33. Anda, R. F., Whitfield, C. L., Felitti, V. J., Chapman, D., Edwards, V. J., Dube, S. R., \& Williamson, D. F. (2002). Adverse childhood experiences, alcoholic parents, and later risk of alcoholism and depression. Psychiatric Services (Washington, D.C.), 53(8), 1001-1009.

34. Jewkes, R. K., Dunkle, K., Nduna, M., Jama, P. N., \& Puren, A. (2010). Associations between childhood adversity and depression, substance abuse and HIV and HSV2 incident infections in rural South African youth. Child Abuse \& Neglect, 34(11), 833-841.

35. Dube, S. R., Anda, R. F., Felitti, V. J., Croft, J. B., Edwards, V. J., \& Giles, W. H. (2001). Growing up with parental alcohol abuse: Exposure to childhood abuse, neglect, and household dysfunction. Child Abuse \& Neglect, 25(12), 1627-1640.

36. Substance Abuse and Mental Health Services Administration. (n.d.). Aderse Childhood Experiences.2014.

37. Dube, Shanta R., Miller, J. W., Brown, D. W., Giles, W. H., Felitti, V. J., Dong, M., \& Anda, R. F. (2006). Adverse childhood experiences and the association with ever using alcohol and initiating alcohol use during adolescence. Journal of Adolescent Health, 38(4), 444.e1-444.e10.

38. WHO Adverse Childhood Experiences International Questionnaire (ACE-IQ) ACEs. Available: https:// www.who.int/violence_injury_prevention/violence/activities/ adverse_childhood_experiences/en/

39. Jernigan, David H \& World Health Organization. Management of Substance Dependence Team. (2001). Global status report: alcohol and young people / David H. Jernigan. World Health Organization. Available: https://apps.who.int/iris/ handle/10665/66795

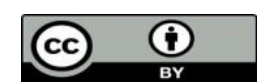

This work is licensed under Creative Commons Attribution 4.0 License

To Submit Your Article Click Here: Submit Article 29.

DOI: $10.31579 / 2688-7517 / 017$
Ready to submit your research? Choose Auctores and benefit from:

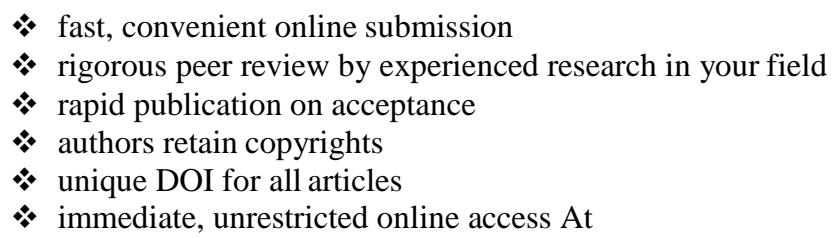

Auctores, research is always in progress.

Learn more www.auctoresonline.org/journals/addiction-research-andadolescent-behaviour 